\title{
GENOTYPE $\times$ ENVIRONMENT INTERACTION AND STABILITY ANALYSES CONCERNING THE YIELD AND QUALITY CHARACTERISTICS OF PROMISING POTATO (SOLANUM TUBEROSUM) GENOTYPES
}

\author{
KARAN, Y. B. ${ }^{*}$ - YILMAZ, G. \\ Department of Field Crop Science, Faculty of Agriculture, Tokat Gaziosmanpasa University, \\ 60250 Tokat, Turkey \\ *Corresponding author \\ e-mail: ybkaran@gmail.com \\ (Received 27 $7^{\text {th }}$ Aug 2020; accepted $18^{\text {th }}$ Dec 2020)
}

\begin{abstract}
This experiment was carried out in three different locations with different environmental characteristics such as altitude, soil structure and precipitation in the Central Black Sea Region in Turkey between 2017-2018. The aim of this study was to investigate performance, dry matter ratio and total tuber yield of 15 different promising potato clones and five different potato commercial cultivars in various environments. The average tuber yields across the environments was 32.44 ton/ha while the average of standard cultivars was 35.13 ton/ha and average of advanced clones was 31.54 ton/ha. The mean dry matter ratio was $19.64 \%$, which was $20.22 \%$ for commercial varieties and $20.03 \%$ for advanced clones. In terms of the stability and genotype $\times$ environment interaction for tuber yield, regression coefficients varied from $\beta \mathrm{i}=0.10$ to 3.39. PAI-8-857, PAI-8-3-15, PAI-8-6-35 and PAI-8-5-34 were closest to $\beta \mathrm{i}=1$ in all environments in respect of the general average and regression coefficient. PAI-8-857 and GOU 6/28 were better suited to grow in all environments. The dry matter values were also subjected to stability and genotype $\times$ interaction analyses. The regression coefficients varied from $\beta i=0.06$ to 2.76 . PAI-8-8-57 clone had higher dry matter content than other genotypes under suitable conditions.
\end{abstract}

Keywords: adaptation, altitude, clones, dry matter content, regression coefficient, tuber yield

\section{Introduction}

Potato, Solanum tuberosum, is estimated to have been cultured by selection from wild species found in the Andes in South America about 10,000 years ago. It is the third most important food crop (FAO, 2018). Potato is cultivated in more than 125 countries. Almost $52 \%$ of the total cultivation area lies in the temperate region in Europe, $34 \%$ of Asia, and $14 \%$ of Africa. The total world potato production was at 368.2 million tons in 2018 (FAO, 2018). Turkey is one of the lowland tropics, and the nineteenth largest producer of potato in the World. Turkey is Middle East's largest producer after Iran, with a production of almost 4.6 million tons in 2018 (FAO, 2018).

Potatoes are cultivated in various environments (Haverkort, 1990). Potatoes are grown in a wide area from the sea level up to elevations of $4000 \mathrm{~m}$. The maximum capacity and genuine tuber dry matter contents and tuber yield are acquired in areas with mild climates (Van der Zaag, 1984; Stol et al., 1991). The dry matter content of potato tubers ranges from 18 and $28 \%$ depending on the genotype and environment (Er and Uranbey, 1998).

Genotype and environment interactions are correlated with the performance of genotypes that indicate stability when planted in various environments. Ruswandi et al. (2008) reported selection of high-efficiency and quality genotypes based on multi environment testing. 


$$
-550 \text { - }
$$

According to Roostaei et al. (2014), the Genotype and environment interactions factor is a major issue faced by plant breeders in plant breeding programs. GEI is essential for the acquirement of new and superior breeding lines as reported by many research results (Niringiye et al., 2014; Hongyu et al., 2014). Important features of an optimal variety include high yield stability under adverse environmental conditions. Furthermore, advanced crop cultivars need to have higher yield levels as well as in other features and this superiority should be expressed in the primary areas where the crop is cultivated (Martin et al., 1988).

The aim of this study was to evaluate the dry matter content and total tubers yields of fifteen promising potato clones and five commercial varieties under at three different locations in the Middle Black Sea Region in Turkey in 2017-2018 for genotype environmental interactions and stability analyses.

\section{Materials and methods}

This investigation was conducted in Erbaa (276 m - $294 \mathrm{~m})$, Kazova (571 m) and Artova (1191 m), Middle Black Sea Region in Turkey, during growing seasons of 20172018 years. The multi locational trials were carried out at three locations and two years that differed with respect to soil type, vegetation, annual precipitation and temperatures and elevations (Table 1). Accordingly, the trial in the geographical field position in the first year Tokat-Erbaa; there are $40.58^{\circ}$ north latitude and $36.89^{\circ}$ eastern longitude. The altitude is $276 \mathrm{~m}$. In the second year, $40.53^{\circ}$ north latitude and $36.93^{\circ}$ eastern longitude, altitude is $291 \mathrm{~m}$. The field trial area in Tokat-Kazova is between $40.33^{\circ}$ north latitude and $36.36^{\circ}$ eastern longitude geographically location, altitude is $571 \mathrm{~m}$. The TokatArtova between $40.13^{\circ}$ and $36.33^{\circ}$ east longitude and north latitude and altitude is $1191 \mathrm{~m}$.

Table 1. Description of the experimental locations. (Source: Turkish State Meteorological Service)

\begin{tabular}{|c|c|c|c|c|c|c|c|c|c|c|}
\hline \multirow{2}{*}{ Location } & \multicolumn{2}{|c|}{ Altitude (m) } & \multicolumn{2}{|c|}{ Soil type } & \multicolumn{3}{|c|}{ Average precipitation $(\mathbf{m m})$} & \multicolumn{3}{|c|}{$\begin{array}{l}\text { Min. temperature/mean } \\
\text { annual max. }\left({ }^{\circ} \mathrm{C}\right)\end{array}$} \\
\hline & 2017 & 2018 & 2017 & 2018 & 2017 & 2018 & $\begin{array}{c}\text { Long term } \\
(1964-2017)\end{array}$ & 2017 & 2018 & \begin{tabular}{|c|} 
Long term \\
$(1964-2017)$
\end{tabular} \\
\hline Tokat-Erbaa & 276 & 294 & Silty clay loam & Silty clay loam & 408.5 & 406.6 & 488.4 & \begin{tabular}{|c|}
$2.7^{\circ} \mathrm{C}$ \\
$/ 25.9^{\circ} \mathrm{C}$ \\
\end{tabular} & \begin{tabular}{|c|}
$6.2^{\circ} \mathrm{C}$ \\
$125.3^{\circ} \mathrm{C}$ \\
\end{tabular} & $\begin{array}{c}4.0^{\circ} \mathrm{C} \\
123.9^{\circ} \mathrm{C}\end{array}$ \\
\hline Tokat-Kazova & 571 & 571 & Clay loam & Clay loam & 391.9 & 329.9 & 433.4 & \begin{tabular}{|c|}
$0.4^{\circ} \mathrm{C}$ \\
$/ 24.5^{\circ} \mathrm{C}$ \\
\end{tabular} & \begin{tabular}{|c|}
$4.4^{\circ} \mathrm{C}$ \\
$/ 23.8^{\circ} \mathrm{C}$ \\
\end{tabular} & $\begin{array}{c}1.7^{\circ} \mathrm{C} \\
/ 22.2^{\circ} \mathrm{C}\end{array}$ \\
\hline Tokat-Artova & 1191 & 1191 & Sandy clay loam & Sandy clay loam & 372.4 & 464.1 & 464.1 & \begin{tabular}{|l|}
$-3.9^{\circ} \mathrm{C}$ \\
$/ 20.6^{\circ} \mathrm{C}$
\end{tabular} & \begin{tabular}{|c|}
$0.7^{\circ} \mathrm{C}$ \\
$/ 19.5^{\circ} \mathrm{C}$
\end{tabular} & $\begin{array}{l}-3.2^{\circ} \mathrm{C} \\
/ 18.0^{\circ} \mathrm{C}\end{array}$ \\
\hline
\end{tabular}

Weather conditions such as soil, temperature and rainfall data were recorded during the experimental years and long-term period are presented in Table 1. In all locations, average temperatures were higher than the long-term averages in both years. On the other hand, total precipitations were lower compared to the long-term values in both years. The total precipitation was $408.5 \mathrm{~mm}$ in Erbaa location in 2017. In 2018, total precipitation was $406.6 \mathrm{~mm}$ in Erbaa location. In Tokat-Erbaa temperature range was $2.7{ }^{\circ} \mathrm{C}$ and $25.9{ }^{\circ} \mathrm{C}$ in 2017, and $6.2{ }^{\circ} \mathrm{C}$ and $25.3{ }^{\circ} \mathrm{C}$ in 2018. Tokat Kazova had average annual rainfall of $329.9 \mathrm{~mm}$ in 2017 and $433.4 \mathrm{~mm}$ in 2018. Also, in Tokat 
Kazova in the first year of experiment minimum and maximum temperature $0.4{ }^{\circ} \mathrm{C}$ and $24.5{ }^{\circ} \mathrm{C}$, respectively. As for the second year of experiment minimum and maximum temperature in Tokat Kazova location was $4.4^{\circ} \mathrm{C}$ and $23.8^{\circ} \mathrm{C}$ respectively. Total annual precipitation in Tokat-Artova location was $464.1 \mathrm{~mm}$ in the first year and $464.1 \mathrm{~mm}$ in the second year. The minimum and maximum temperature values in Tokat Artova were $-3.9{ }^{\circ} \mathrm{C}$ and $20.6{ }^{\circ} \mathrm{C}$ in 2017 , and $0.7^{\circ} \mathrm{C}$ and $19.5^{\circ} \mathrm{C}$ in 2018 , respectively.

\section{Plant material used in experiment}

In the experiment, 15 different promising potato breeding lines and 5 different commercially available cultivars were used as plant material (Table 2).

Table 2. Plant material used in the experiment

\begin{tabular}{|c|c|c|c|c|c|}
\hline Number & Genotype name & Pedigree & Maturity & Breeding institution & Tuber flesh color \\
\hline 1 & PAI-8-1-6 & Provento $\times$ Marfona & Early to intermediate & PAI & Light yellow \\
\hline 2 & PAI-8-3-15 & Agria $\times$ Van Gogh & Intermediate to late & PAI & Yellow \\
\hline 3 & PAI-8-5-34 & Atlantic $\times$ Hermes & Early & PAI & Yellow \\
\hline 4 & PAI-8-6-35 & Agria $\times$ Granola & Very early to early & PAI & Yellow \\
\hline 5 & PAI-8-7-49 & Atlantic $\times$ R. Russet & Early to intermediate & PAI & Cream \\
\hline 6 & PAI-8-8-57 & Provento $\times$ Granola & Early to intermediate & PAI & Yellow \\
\hline 7 & PAI-8-9-63 & L. Rosetta $\times$ Granola & Very early to early & PAI & Light yellow \\
\hline 8 & PAI-8-11-79 & Atlantic $\times$ Laura & Early to intermediate & PAI & Light yellow \\
\hline 9 & PAI-8-12-86 & Atlantic $\times$ Granola & Early to intermediate & PAI & Cream \\
\hline 10 & PAI-8-15-138 & Atlantic $\times$ Konsul & Early & PAI & Light yellow \\
\hline 11 & GOÜ-3/110 & Serrana $\times$ TS-9 & Late & GOU & Yellow \\
\hline 12 & GOÜ-4/4 & Granola $\times$ TS-2 & Intermediate to late & GOU & Light yellow \\
\hline 13 & GOÜ-6/28 & Serrana $\times$ LT -7 & Intermediate to late & GOU & Light yellow \\
\hline 14 & GOÜ-7/12 & Serrana $\times$ TS- 4 & Intermediate to late & GOU & Cream \\
\hline 15 & GOÜ-10/15 & MF-1 $\times$ LT-7 & Intermediate to late & GOU & Cream \\
\hline 16 & Agata & BM5272 $\times$ Sirco & Very early to early & Agrico & Light yellow \\
\hline 17 & Alegria & Flava×_@ & Very early & & Yellow \\
\hline 18 & Agria & Quarta $\times$ Semlo & Intermediate to late & Agrico & Yellow \\
\hline 19 & Lady Claire & Agria $\times \mathrm{KW} 78-34-470$ & Early & Meijer Seed Potatoes Ltd & Light yellow \\
\hline 20 & Lady Olympia & Agria $\times$ KW 78-34-470 & Early & Meijer Seed Potatoes Ltd & Yellow \\
\hline
\end{tabular}

PAI: Potato Research Institute, Nigde-Turkey; GOU: Gaziosmanpasa University Faculty of Agriculture

\section{Methods}

At all locations, the study was arranged in a completely randomized block design. The trial consisted of three replications. Potato genotypes of tubers were planted in Erbaa in early March, in Kazova in the second decade of April, and in Artova in May in the first decade of May in both years. For both years and both sites, the plot size for each genotype consists of 4 rows of $6 \mathrm{~m}$. length. Planting of potato tubers was performed at spacing of $70 \mathrm{~cm}$ between rows and $30 \mathrm{~cm}$ between plants. At each site and year, plots were fertilized with $120 \mathrm{~kg}$ nitrogen, phosphorus, potassium ha ${ }^{-1}$ in the form of 15:15:15. The entire rate of phosphorus and potassium were applied at the time of planting. Nitrogen fertilizer was applied at $80 \mathrm{~kg} / \mathrm{ha}$ at the beginning of tuber formation. (Tugay et al., 1995). The potato varieties and promising clones were watered to maintain adequate moisture levels with drip irrigation. According to FAO, for high yields, the crop water requirements for a 120 to 150 day crop are 500 to $700 \mathrm{~mm}$, 
depending on climate. The water needs of potato plants are generally lower during the first stages of the plant development and they gradually increase towards maturation and the later stages of tuber growth (FAO, 2020). In both years, irrigation was started in Erbaa in mid-May, in Kazova in early June, and in Artova in mid-June. Irrigation intervals were approximately 10 days in all environments. The amount of water applied varied between 50 and $100 \mathrm{~mm}$ per event to bring the soil moisture level to field capacity. Cultural and chemical practices such as weeding and pest-control were used in all locations and years. The fields were harvested when the plants reached harvest maturity. Tubers were harvested in early September in Erbaa, at end of September in Kazova and in the mid of October in Artova in both years. After harvest, the tubers were stored for 8 weeks. Dry matter content was measured as weight in water, which can be turned into specific gravity by the formula: Specific Gravity $\left(\mathrm{gcm}^{-3}\right)=$ Weight in air / (Weight in air-Under water weight). $5 \mathrm{~kg}$ tubers were randomly taken from each location with water then weighed first in air and then in water. (Meijers and Van Veldhuisen, 1972). Total tuber yield per hectare was calculated using tuber weight of center rows.

\section{Evaluation of the data}

\section{Statistical analyses}

The experimental design used was a randomized complete block design with three replications at each location and year. An analysis of variance (ANOVA) was done for each potato genotype and cultivar separately as randomized complete block design. Combined ANOVA result of each location and years showed significant $(\mathrm{P}<0.01)$ genotypic differences for dry matter content and total tuber yield. Potato genotypes and cultivars were compared using Duncan statistical test with SPSS software (Duzgunes et al., 1987).

\section{Stability analysis or parametric approach}

Genotype $\times$ environment interaction variances should be statistically significant before performing stability analysis. Because of this, combining multiple experiments and repeated experiments in a year, the genotype $\times$ location, genotype $\times$ year and genotype $\times$ location $\times$ year interaction in the variance analysis chart should be identified by checking the $\mathrm{F}$ test by means of the $\mathrm{F}$ test (Arshad, 1990). Yield stability and adaptation terms are often used in different senses (Lin et al., 1986; Becker and Leon, 1988). The process to be performed after the interactions are important is to create a bilateral genotype $\times$ environment interaction chart by using the mean values of the genotypes in the environment (İkiz, 1972;1976; Y1ldırım et al., 1979 and Arshad, 1990). From this chart, the stability criteria such as the regression coefficients on the environmental mean of the genotypes and the squared deviations of this regression can be calculated (Finlay and Wilkinson 1963). From this table, stability criteria such as regression coefficients of genotypes $(\mathrm{Y})$ on environment $(\mathrm{X})$ can be calculated later (Arshad, 1990), where: $X_{i j}=$ The mean of $i^{\text {th }}$ genotype at the $\mathrm{j}^{\text {th }}$ environment; $\bar{X}$ ..$=$ Genotypes general average in all environment; $g_{i}=$ Effect of $i^{t^{\text {th }}}$ genotype; $e_{j}=$ Effect of $\mathrm{j}^{\text {th }}$ environment; (ge) $\mathrm{ij}=\mathrm{i}$. genotype $\mathrm{j}$. interacts with the environment and is estimated by (ij- i.- .j + ..).

The main parameters of genotype $\times$ environment analyses are summarized in Table 3 (Lin et al., 1986). 
Table 3. Detailed bilateral chart for genotype environment interaction

\begin{tabular}{|c|c|c|c|c|c|}
\hline Genotypes & $\mathbf{E}_{1}$ & $\mathbf{E}_{\mathrm{j}}$ & $\mathbf{E}_{\mathrm{c}}$ & Genotype average & Effect of genotype $\left(\mathrm{g}_{\mathrm{ii}}\right)$ \\
\hline $\mathbf{G}_{1}$ & $\mathrm{x}_{11}$ & $X_{1 j}$ & $x_{1 e}$ & $\bar{X}_{1 .}$ & $\bar{X}_{1 .}-\bar{X}$ \\
\hline $\mathbf{G}_{\mathrm{i}}$ & $x_{i 1}$ & $\mathrm{x}_{\mathrm{ij}}$ & $\mathrm{x}_{\mathrm{ie}}$ & $\bar{X}_{\mathrm{i} .}$ & $\bar{X}_{\mathrm{i} .}-\bar{X}_{. .}$ \\
\hline$G_{g}$ & $\mathrm{x}_{\mathrm{g} 1}$ & $\mathrm{x}_{\mathrm{gj}}$ & $\mathrm{x}_{\mathrm{ge}}$ & $\bar{X}_{\mathrm{g}}$ & $\bar{X}_{\mathrm{g} \cdot-} \bar{X}_{. .}$ \\
\hline Environment average & $\bar{X}_{.1}$ & $\bar{X}_{\cdot \mathrm{j}}$ & $\bar{X}_{. q}$ & $\bar{X}$.. general average & \\
\hline Effect of environment $\left(E_{J}\right)$ & $\bar{X}_{.1}-\bar{X}$ & $\bar{X}_{\mathrm{j} j}-\bar{X}$ & $\bar{X}_{\mathrm{e}}-\bar{X}$ & & \\
\hline
\end{tabular}

According to Finlay and Wilkinson (1963), the regression of the genotype values that each genotype received in different environments was calculated on environmental averages.

$$
\beta \mathrm{i}=\sum^{a}=1(\mathrm{Xij}-\bar{X} \mathrm{i} .)(\bar{X} \cdot \mathrm{j}-\bar{X} . .) / \sum_{g}^{a}(\bar{X} \cdot \mathrm{j}-\bar{X} . .) 2
$$

where: $\mathrm{i}=$ genotypes; $\mathrm{j}=$ environments; $\mathrm{X}_{\mathrm{iJ}}-\bar{X}_{\mathrm{i} .}=\mathrm{It}$ is the difference between the phenotype value of the I; genotype and the mean of the genotype on all environmental; $\bar{X}_{. j} \bar{X} . .=$ effect of $\mathrm{j}^{\text {th }}$ environment; $\beta \mathrm{i}$ : regression coefficient for the response of the $\mathrm{i}^{\text {th }}$ genotype to varying environments; q: number of environments.

The regression coefficient $(\beta i)$ were used as measures of stability, with respect to Finlay and Wilkinson (1963). Regression coefficients approaching 1.0 show mean stability, but to determine adaptability, the genotype should always be associated and interpreted with the average total tuber yield and dry matter content.

Genotypes with regression coefficients close to 1.0 and high total tuber yields and dry matter contents are adapted to all environments. Genotypes with low average total tuber yields and dry matter content with regression coefficients close to 1.0 are poorly adapted to all environments regression coefficients over 1.0 means that genotypes have higher sensitivity to environmental variation with below average stability and great specific adaptability to high yielding environments.

Regression coefficients below 1.0 represents a measure of stability against environmental change and more specific adaptation to low efficiency environments. Confidence limits are calculated by multiplying the standard error of the mean with the appropriate t-value. The t-value is determined by the probability and the degrees of freedom (n-1). Figure 1 illustrates genotypic patterns when regression is plotted against genotypic performance.

\section{Results and discussion}

\section{Total tuber yield (ton/ha)}

The results in Table 4 showed that total tuber yield per hectare. Since each year and location were regarded as an environment in respect of stability, the study was conducted with 15 advanced generation clones and 5 commercial varieties in six environments. Total tuber yields were notably influenced by genotypes and different environments (Table 4). Accordingly, the overall mean of the test in regards of tuber 
yield 32.44 ton/ha., average of standard commercial cultivars 35.13 ton/ha., average of advanced clones was 31.54 ton/ha.

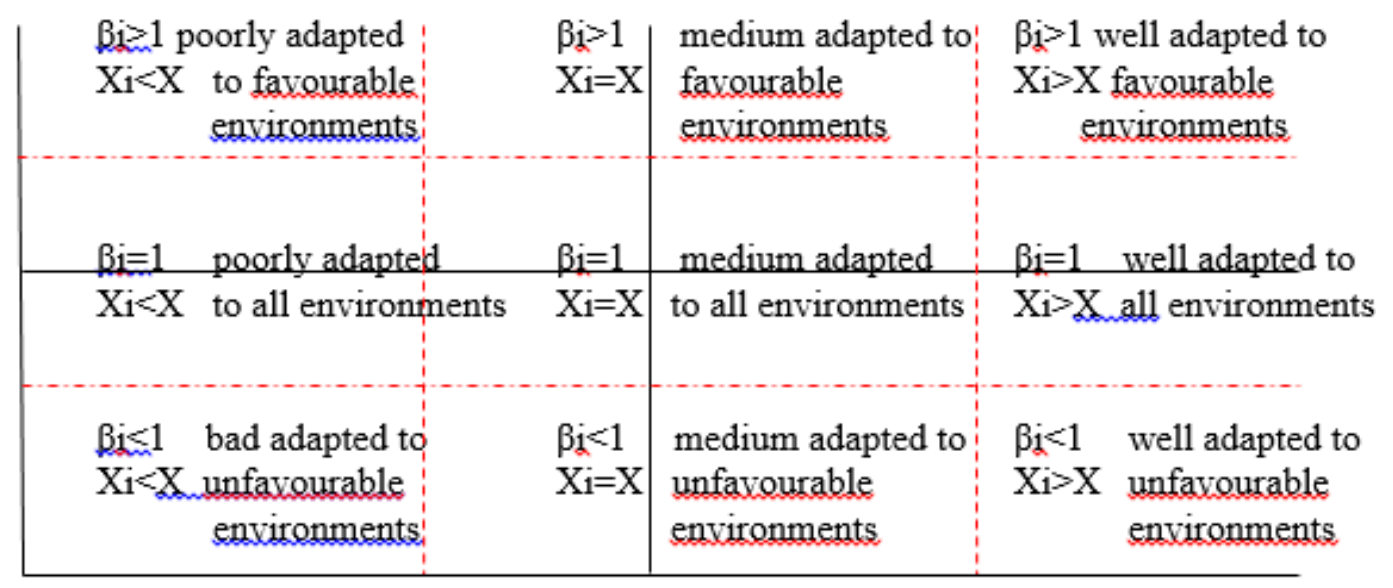

Figure 1. Mathematical and verbal correction of genotypic adaptation

In 2017, the tuber yield of genotypes ranged from 5.46 ton/ha (PAI-8-9-63) to 42.67 ton/ha (Agria) in Erbaa, from 9.30 ton/ha (GOU 4/4) to 39.28 ton/ha (Agata) in Kazova, and from 7.44 ton/ha (PAI-8-9-63) to 49.31 ton/ha (PAI-8-1-6) in Artova. In 2018 , the total tuber yield of genotypes ranged from 18.00 ton/ha (PAI-8-9-63) to 48.56 ton/ha (GOU 7/12) in Erbaa, from 17.44 ton/ha (PAI-8-9-63) to 46.96 ton/ha (PAI-8-8-57) in Kazova, and from 13.81 ton/ha (PAI-8-9-63) to 50.98 ton/ha (PAI-8-857) in Artova. PAI-8-8-57 and GOU 6/28 clones had high yields in all locations and years (Table 4).

The highest total tuber yield occurred in Erbaa in Agria variety in both years. The highest tuber yield produced in Kazova from GOU 6/28 (39.28 ton/ha) in 2017. Second year of this study, the results showed that the highest total tuber yield were belonged to the PAI-8-8-57 (46.96 ton/ha). However, PAI-8-857 and GOU 6/28 (46.62 ton/ha) were statistically in the same group. In Artova, first year of study, the tuber yields were highest with PAI-8-1-6, PAI-8-8-57, GOU 6/28, PAI -8-5-34, Alegria, Lady Olympia, PAI-8-7-49, PAI-8-12-86 and GOU 10/15. Also, these genotypes were statistically in the same group. The highest tuber yield produced in Artova from PAI-8-8-57 (50.98 ton/ha) in 2018. In terms of locations, the highest average tuber yields in decreasing order were in Artova, Kazova and Erbaa locations in both years (Table 4).

In parallel with this study, yields of 13 potato clones were investigated by Hajianfar et al. (2017). These potato clones had yield levels in the range of 35.19-41.22 t/ha. These clones were significantly superior to the check cultivar, Agria whose yield was 28.58 ton/ha, and other potato clones.

In a potato breeding program, three promising clones with good quality and quantity features were defined among 18 superior potato genotypes in Iran (Hassanpanah and Hassanabadi, 2012). In another study, stability of 13 promising potato clones for high total tuber yield in different environmental condition was studied. Among the potato clones, three with high stability performance and good characteristics compared to the check cultivars were selected (Hassanpanah and Hassanabadi, 2014). 
When all environments were considered separately, PAI-8-8-57 and GOU 6/28 clones produced highest tuber yields compare to other clones. In all environments, genotypic differences were statistically significant $(\mathrm{P}<0.01)$ for tuber yields.

According to Finlay and Wilkinson (1963) a regression coefficient closest at $\beta \mathrm{i}=1$ shows average sensitiveness. When this is correlated with high average total tuber yield the genotype has general adaptively and when correlated with low average total tuber yield, the genotype has poor adaptability. High and stable yield levels in potato tubers are always desirable. It is also reported that tuber yield is one of the most important components for the person trying to define an ideal variety (Hoopes and Plaisted, 1987).

When the findings of total tuber yield were investigated in regards of stability and GEI, and the regression coefficients varied from $\beta \mathrm{i}=0.10$ to 3.39. Accordingly, PAI-8857, PAI-8-3-15, PAI-8-6-35 and PAI-8-5-34 were closest to $\beta \mathrm{i}=1$ in the all environmental in respect to the general average and regression coefficient. PAI-8-8-57 and GOU 6/28 were better suited to grow than other clones in all environmental (Table 4 and Fig. 2).

Table 4. Total tuber yield (ton/ha) and regression coefficients ( $\beta$ i) of clones and cultivars in all environments

\begin{tabular}{|c|c|c|c|c|c|c|c|c|c|c|c|c|c|c|c|}
\hline \multirow{3}{*}{$\begin{array}{c}\text { Genotype } \\
\text { Agata }\end{array}$} & \multicolumn{4}{|c|}{ Erbaa } & \multicolumn{4}{|c|}{ Kazova } & \multicolumn{4}{|c|}{ Artova } & \multirow{3}{*}{\begin{tabular}{|c|}
$\begin{array}{c}\text { Genotype } \\
\text { average }\end{array}$ \\
31.19 \\
\end{tabular}} & \multirow{3}{*}{\begin{tabular}{|c|}
$\begin{array}{c}\text { Effect of } \\
\text { genotype }\left(\mathbf{g}_{\mathrm{ii}}\right)\end{array}$ \\
-1.24 \\
\end{tabular}} & \multirow{3}{*}{$\begin{array}{c}\boldsymbol{\beta i} \\
0.50\end{array}$} \\
\hline & \multicolumn{2}{|c|}{2017} & \multicolumn{2}{|c|}{2018} & \multicolumn{2}{|c|}{2017} & \multicolumn{2}{|c|}{2018} & \multicolumn{2}{|c|}{2017} & \multicolumn{2}{|c|}{2018} & & & \\
\hline & 25.73 & $d-h^{* *}$ & 27.65 & bcd $^{* *}$ & 39.28 & $a^{* *}$ & 39.62 & $a b c^{* *}$ & 25.16 & $\mathrm{bc}^{* *}$ & 29.71 & $\mathrm{de}^{* *}$ & & & \\
\hline Alegria & 33.61 & a-e & 38.60 & $\mathrm{ab}$ & 37.72 & $\mathrm{ab}$ & 39.81 & $\mathrm{abc}$ & 44.35 & $\mathrm{a}$ & 40.38 & a-d & 39.08 & 6.64 & 0.57 \\
\hline Agria & 42.67 & $\mathrm{a}$ & 47.85 & $\mathrm{a}$ & 26.20 & $\mathrm{~cd}$ & 42.25 & $\mathrm{ab}$ & 36.55 & $\mathrm{ab}$ & 44.72 & $a b c$ & 40.04 & 7.61 & 0.64 \\
\hline Lady Claire & 30.21 & b-g & 35.85 & $a b c$ & 25.80 & $\mathrm{c}$ & 30.85 & bcd & 21.91 & $\mathrm{~cd}$ & 35.95 & b-e & 30.09 & -2.34 & 0.55 \\
\hline Lady Olympia & 21.21 & f-h & 28.50 & bcd & 36.60 & $\mathrm{ab}$ & 38.51 & $a b c$ & 43.16 & $\mathrm{a}$ & 43.51 & a-d & 35.25 & 2.81 & 1.75 \\
\hline $\begin{array}{l}\text { Cultivar } \\
\text { average }\end{array}$ & \multicolumn{2}{|c|}{30.68} & \multicolumn{2}{|c|}{35.69} & \multicolumn{2}{|c|}{33.12} & \multicolumn{2}{|c|}{38.20} & \multicolumn{2}{|c|}{34.23} & \multicolumn{2}{|c|}{38.85} & 35.13 & & \\
\hline GOÜ 3/110 & 20.75 & f-h & 26.50 & bcd & 29.57 & cde & 27.27 & cde & 17.27 & cde & 22.23 & ef & 23.93 & -8.51 & 0.10 \\
\hline GOÜ 4/4 & 22.89 & $e-h$ & 37.42 & $\mathrm{ab}$ & 9.30 & $\mathrm{f}$ & 19.49 & de & 9.49 & de & 24.14 & ef & 20.45 & -11.98 & 0.31 \\
\hline GOÜ 6/28 & 33.61 & a-e & 38.50 & $\mathrm{ab}$ & 39.28 & $\mathrm{a}$ & 46.62 & $\mathrm{a}$ & 46.62 & $\mathrm{a}$ & 49.65 & $\mathrm{ab}$ & 42.38 & 9.94 & 1.88 \\
\hline GOÜ 7/12 & 40.40 & $\mathrm{ab}$ & 48.56 & $\mathrm{a}$ & 27.18 & $\mathrm{c}$ & 35.82 & $a b c$ & 10.83 & $\mathrm{de}$ & 39.95 & $a-d$ & 33.79 & 1.35 & 0.20 \\
\hline GOÜ 10/15 & 9.24 & $\mathrm{ij}$ & 18.50 & $\mathrm{~d}$ & 17.77 & $\mathrm{~d}$ & 40.71 & $\mathrm{ab}$ & 40.71 & $\mathrm{a}$ & 42.52 & a-d & 28.24 & -4.19 & 3.39 \\
\hline PAI-8-1-6 & 19.11 & $g-i$ & 22.01 & $\mathrm{~cd}$ & 33.37 & $a b c$ & 30.80 & bcd & 49.31 & $\mathrm{a}$ & 43.93 & a-d & 33.09 & 0.65 & 1.69 \\
\hline PAI -8-3-15 & 30.28 & b-g & 35.88 & $a b c$ & 31.26 & $\mathrm{abc}$ & 38.55 & $a b c$ & 26.31 & $\mathrm{bc}$ & 39.28 & a-d & 33.59 & 1.16 & 0.96 \\
\hline PAI -8-5-34 & 30.95 & b-f & 37.42 & $\mathrm{ab}$ & 34.08 & $a b c$ & 30.52 & bcd & 44.32 & $\mathrm{a}$ & 46.45 & $a b c$ & 37.29 & 4.85 & 0.85 \\
\hline PAI-8-6-35 & 33.90 & a-e & 31.09 & bcd & 30.61 & $a b c$ & 37.34 & $a b c$ & 37.34 & $a b$ & 43.90 & $a-d$ & 35.70 & 3.26 & 0.96 \\
\hline PAI-8-7-49 & 15.51 & $h-j$ & 24.83 & bcd & 33.83 & $a b c$ & 42.45 & $\mathrm{ab}$ & 42.45 & $\mathrm{a}$ & 40.79 & a-d & 33.31 & 0.87 & 2.31 \\
\hline PAI-8-8-57 & 38.50 & $a b c$ & 35.01 & $a b c$ & 37.49 & $\mathrm{ab}$ & 46.96 & $\mathrm{a}$ & 46.96 & $\mathrm{a}$ & 50.98 & $\mathrm{a}$ & ( & 10.21 & 1.29 \\
\hline PAI-8-9-63 & 5.46 & $\mathrm{j}$ & 18.00 & $\mathrm{~d}$ & 13.07 & ef & 17.44 & $\mathrm{e}$ & 7.44 & $\mathrm{e}$ & 13.81 & $\mathrm{f}$ & 12.54 & -19.90 & 0.82 \\
\hline PAI-8-11-79 & 27.92 & c-g & 32.49 & $\mathrm{bc}$ & 36.49 & $\mathrm{ab}$ & 37.70 & $a b c$ & 37.70 & $\mathrm{ab}$ & 34.04 & cde & 34.39 & 1.96 & 0.56 \\
\hline PAI-8-12-86 & 34.50 & a-d & 25.00 & bcd & 27.52 & $\mathrm{c}$ & 41.15 & $\mathrm{ab}$ & 41.15 & $\mathrm{a}$ & 34.39 & cde & 33.95 & 1.52 & 0.59 \\
\hline PAI-8-15-138 & 23.16 & d-h & 30.05 & bcd & 34.55 & $\mathrm{abc}$ & 36.18 & $a b c$ & 16.18 & cde & 26.43 & ef & 27.76 & -4.68 & 0.46 \\
\hline Clone average & 25. & & 30. & .75 & 29.0 & & 35 & .27 & 31. & 60 & 36. & & 31.54 & & \\
\hline \multirow{2}{*}{$\begin{array}{l}\text { Environmental } \\
\text { average }\end{array}$} & \multirow{2}{*}{\multicolumn{2}{|c|}{26.98}} & \multirow{2}{*}{\multicolumn{2}{|c|}{31.99}} & \multirow{2}{*}{\multicolumn{2}{|c|}{30.05}} & \multirow{2}{*}{\multicolumn{2}{|c|}{36.00}} & \multirow{2}{*}{\multicolumn{2}{|c|}{32.26}} & \multirow{2}{*}{\multicolumn{2}{|c|}{37.34}} & 32.44 & & 1.00 \\
\hline & & & & & & & & & & & & & Conf & fidence interva & \\
\hline $\begin{array}{c}\text { Effect of } \\
\text { environment }\end{array}$ & \multicolumn{2}{|c|}{-5.46} & -0.4 & 45 & -2.3 & & 3.5 & 57 & -0. & 18 & 4.9 & 90 & & & 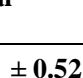 \\
\hline
\end{tabular}

**Significant at $1 \%$ level of probability 
In environments with different characteristics such as altitude, temperature, precipitation and soil types, the findings of the advanced generation clones and varieties with different properties have been examined. According to this GOU 6/28 clone showed well adapted in the favorable environmental. PAI-8-1-6, PAI-8-7-49, GOU 10/15 clones and Lady Olympia cultivar showed medium adapted in the favorable environments. PAI-8-8-57, PAI-8-5-34 clones and Alegria and Agria cultivars showed well adapted in the all environments. PAI-8-6-35, PAI8-12-86, PAI8-3-15, PAI-8-11-79 and Agata, Lady Claire cultivars showed medium adapted in the all environments. PAI-8-9-63 clone cultivar showed poorly adapted in the all environments.

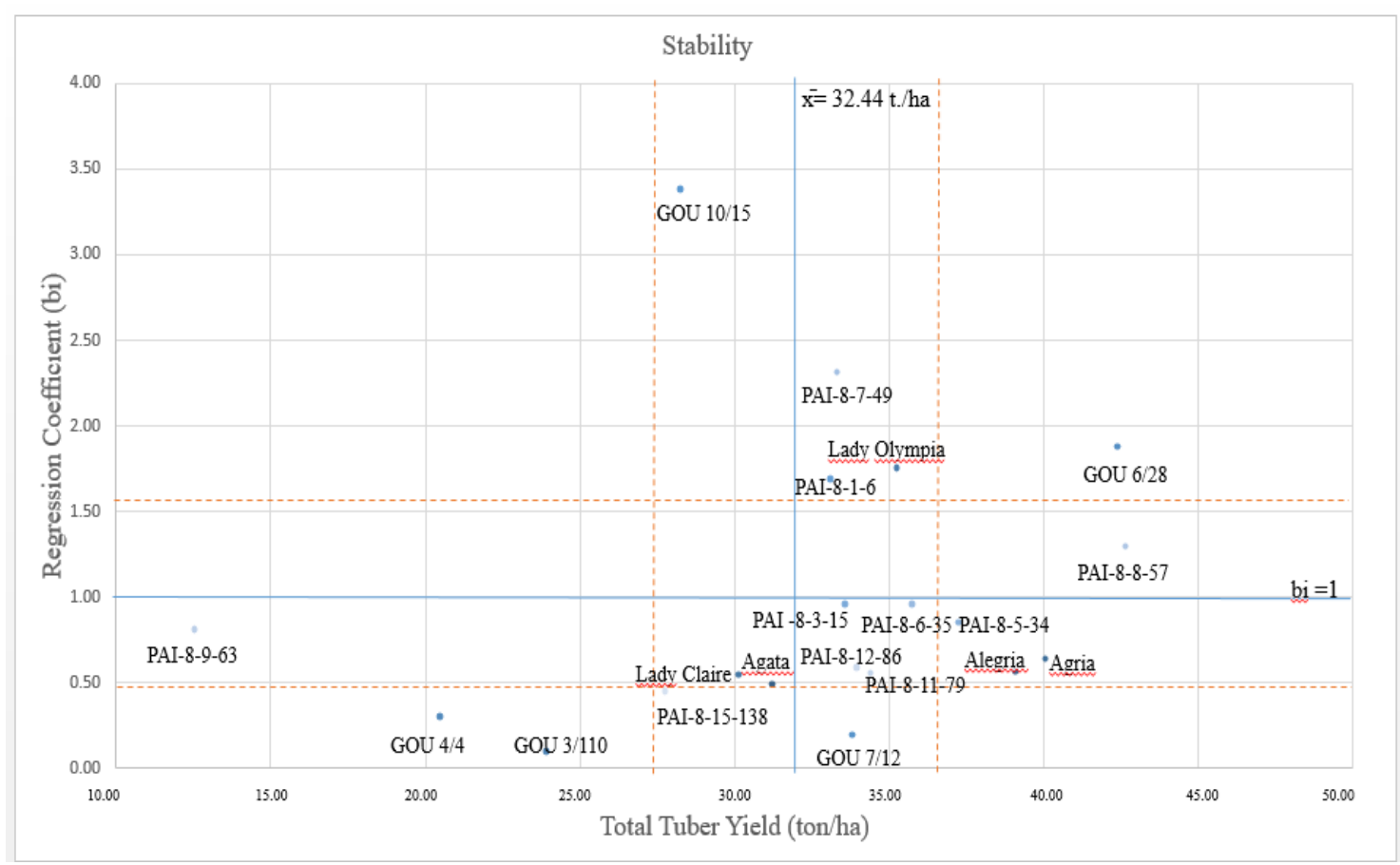

Figure 2. Adaptation classes of clone and varieties of total tuber yield (ton/ha)

While GOU 7/12 and PAI-8-15-138 clones showed medium adapted in the unfavorable environment, GOU 4/4 and GOU 3/110 clones showed poorly adapted in the unfavorable environment (Fig. 2).

\section{Dry matter content (\%)}

In this research, the dry matter percent of the potato clones and cultivars were given in Table 5. Accordingly, first year of this study the overall average of the promising clones and cultivars in regards of the dry matter ratio $20.70 \%$ in Erbaa, $19.07 \%$ in Kazova, $18.21 \%$ in Artova. In the second year of this study, the overall mean of the tubers in regards of the dry matter ratio was $19.92 \%$ in Erbaa, $19.73 \%$ in Kazova, $20.22 \%$ in Artova. The overall mean of the study in regards of dry matter was $19.64 \%$, average of standard commercial varieties $19.47 \%$, mean of promising clones was $19.70 \%$. Dry matter ratios of the 15 promising clones and 5 commercial varieties were different. In this research, the dry matter ratio of the genotypes varied from 17.35 to $21.96 \%$. 


$$
-557 \text { - }
$$

According to Table 5, the maximum dry matter ratio was observed from PAI-8-7-49 clone (\% 21.96) in all genotypes, in all locations and years. Similarly, the highest dry matter was obtained from Lady Olympia (\% 20.62) in all commercial cultivars.

In 2017, the dry matter content of genotypes ranged between 16.93\% (Agata) and 23.37\% (PAI-8-8-57) in Erbaa, between 15.57\% (PAI-8-1-6) and 22.87\% (PAI-8-7-49) in Kazova, and between $17.50 \%$ (PAI-8-12-86) and 21.07\% (PAI-8-7-49) in Artova. In 2018 , the dry matter content of genotypes ranged between $17.20 \%$ (Agata) and $22.87 \%$ (PAI-8-7-49) in Erbaa, between 16.40\% (PAI -8-5-34) and 21.90\% (PAI-8-7-49) in Kazova, and between $17.50 \%$ (PAI-8-12-86) and 22.40\% (PAI-8-7-49) in Artova (Table 5).

Table 5. Total dry matter (\%) and regression coefficients ( $\beta$ i) of clones and cultivars in all environments

\begin{tabular}{|c|c|c|c|c|c|c|c|c|c|c|c|c|c|c|c|}
\hline \multirow{3}{*}{$\begin{array}{c}\text { Genotype } \\
\text { Agata } \\
\end{array}$} & \multicolumn{4}{|c|}{ Erbaa } & \multicolumn{4}{|c|}{ Kazova } & \multicolumn{4}{|c|}{ Artova } & \multirow{3}{*}{\begin{tabular}{|c|}
$\begin{array}{c}\text { Genotype } \\
\text { average }\end{array}$ \\
17.37 \\
\end{tabular}} & \multirow{3}{*}{\begin{tabular}{|c}
$\begin{array}{c}\text { Effect of } \\
\text { genotype }\left(\mathrm{g}_{\mathrm{ii}}\right)\end{array}$ \\
-2.27
\end{tabular}} & \multirow{3}{*}{$\begin{array}{c}\boldsymbol{\beta i} \\
0.69\end{array}$} \\
\hline & \multicolumn{2}{|c|}{2017} & \multicolumn{2}{|c|}{2018} & \multicolumn{2}{|c|}{2017} & \multicolumn{2}{|c|}{2018} & \multicolumn{2}{|c|}{2017} & \multicolumn{2}{|c|}{2018} & & & \\
\hline & 16.93 & $\mathrm{f}^{* *}$ & 17.20 & $\mathrm{~d}^{* *}$ & 19.03 & $\operatorname{cde}^{* *}$ & 17.90 & $\mathrm{cde}^{* *}$ & 14.87 & $f^{* *}$ & 18.30 & $\mathrm{bc}^{* *}$ & & & \\
\hline Alegria & 18.35 & -1 & 18.30 & bcd & 0.10 & bcd & 20.50 & $a b c$ & 18.63 & $\mathrm{bc}$ & 20.50 & $a b c$ & 19.83 & 0.19 & 0.19 \\
\hline Agria & 19.80 & $\mathrm{~d}-1$ & 9.20 & $a-d$ & 9.00 & cde & 20.00 & $\mathrm{abc}$ & 7.43 & cde & 19.70 & $a b c$ & 19.19 & -0.45 & 0.93 \\
\hline Lady Claire & 20.67 & a-e & 19.20 & $a-d$ & 21.47 & $\mathrm{ab}$ & 20.70 & $\mathrm{abc}$ & 18.97 & $a b c$ & 20.90 & $a b c$ & 20.32 & 0.68 & 0.43 \\
\hline Lady Olympia & 0.93 & a-e & 1.10 & $\mathrm{ab}$ & 9.53 & b-e & 1.50 & $\mathrm{a}$ & 18.97 & $a b c$ & 21.70 & $\mathrm{ab}$ & 20.62 & .98 & 1.06 \\
\hline $\begin{array}{l}\text { Cultivar } \\
\text { average }\end{array}$ & \multicolumn{2}{|c|}{19.34} & \multicolumn{2}{|c|}{19.00} & \multicolumn{2}{|c|}{19.83} & \multicolumn{2}{|c|}{20.12} & \multicolumn{2}{|c|}{17.77} & \multicolumn{2}{|c|}{20.22} & 19.47 & & \\
\hline GOU 3/110 & 20.13 & $\mathrm{a}-\mathrm{f}$ & 19.00 & $\mathrm{a}-\mathrm{d}$ & 17.43 & efg & 18.00 & b-e & 17.93 & $\mathrm{~cd}$ & 18.30 & $\mathrm{bc}$ & 18.47 & -1.18 & 0.80 \\
\hline GOU 4/4 & 21.53 & a-e & 0.70 & $a b c$ & 8.37 & def & 19.00 & a-e & 19.50 & $a b c$ & 21.70 & $\mathrm{ab}$ & 20.13 & 0.49 & 1.11 \\
\hline GOU 6/28 & 22.30 & $a-d$ & 20.50 & $a b c$ & 18.20 & def & 20.70 & $a b c$ & 17.47 & cde & 20.10 & $\mathrm{abc}$ & 19.88 & 0.24 & 1.74 \\
\hline GOU 7/12 & 22.50 & $a b c$ & 19.80 & $\mathrm{a}-\mathrm{d}$ & 19.13 & cde & 20.40 & $a b c$ & 15.23 & ef & 21.70 & $\mathrm{ab}$ & 19.79 & 0.15 & 2.79 \\
\hline GOU $10 / 15$ & 19.47 & $b-f$ & 20.70 & $a b c$ & 6.53 & 15 & 21.10 & $a b c$ & 19.40 & $a b c$ & 19.70 & $a b c$ & 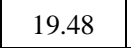 & . & 0.61 \\
\hline PAI-8-1-6 & 19.13 & $c-f$ & 9.50 & a-d & 5.57 & $\mathrm{~g}$ & 5.80 & $\mathrm{e}$ & 16.10 & def & 18.00 & $\mathrm{bc}$ & 17.35 & -2.29 & 1.41 \\
\hline PAI -8-3-15 & 22.97 & ao & 20.70 & $a b c$ & 18.03 & def & 19.70 & $a-d$ & 19.40 & $a b c$ & 20.40 & $a b c$ & 20.20 & 0.56 & 1.41 \\
\hline PAI -8-5-34 & 19.90 & $a-f$ & 19.90 & a-d & 16.63 & $\mathrm{fg}$ & 16.40 & $\mathrm{e}$ & 17.83 & $\mathrm{~cd}$ & 18.80 & $a b c$ & 18.24 & -1.40 & 0.99 \\
\hline PAI-8-6-35 & 22.40 & $a-d$ & 18.00 & $\mathrm{~cd}$ & 20.73 & $\mathrm{bc}$ & 21.40 & $\mathrm{ab}$ & 19.10 & $a b c$ & 20.90 & $\mathrm{abc}$ & 20.42 & 0.78 & 0.90 \\
\hline PAI-8-7-49 & 22.43 & $a-d$ & 0 & $a b$ & 77 & a & 0 & $\mathrm{a}$ & 7 & a & .40 & $\mathrm{a}$ & 6 & 2.32 & 0.32 \\
\hline PAI-8-8-57 & 23.37 & $\mathrm{a}$ & 21.10 & $a b$ & 19.03 & cde & 20.20 & $\mathrm{abc}$ & 18.33 & bcd & 21.00 & $\mathrm{abc}$ & 20.51 & 0.80 & 1.89 \\
\hline PAI-8-9-63 & 20.60 & a-e & 20.70 & $a b c$ & 20.73 & $\mathrm{bc}$ & 19.80 & $a-d$ & 20.47 & $a b$ & 20.90 & $a b c$ & 20.53 & 0.89 & 0.06 \\
\hline PAI-8-11-79 & 18.80 & def & 19.40 & a-d & 20.53 & $\mathrm{bc}$ & 19.90 & $a b c$ & 19.00 & $a b c$ & 20.00 & $\mathrm{abc}$ & 20.06 & 0.41 & 0.22 \\
\hline PAI-8-12-86 & 20.50 & $\mathrm{a}-\mathrm{e}$ & 21.30 & $\mathrm{a}$ & 7.83 & 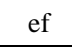 & 16.60 & uc & 5.33 & ef & 17.50 & 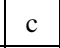 & 10.1 & -1.4 & 1.80 \\
\hline PAI-8-15-138 & 1.30 & $\mathrm{a}-\mathrm{e}$ & 20.50 & $a b c$ & 20.57 & $\mathrm{bc}$ & 21.00 & $\mathrm{abc}$ & 19.17 & $a b c$ & 19.10 & $\mathrm{abc}$ & 20.27 & 0.63 & 0.50 \\
\hline Clone average &. & & 20. & & 18. & & 19 & & 18.3 & & 20. & & 19.70 & & \\
\hline \multirow{2}{*}{$\begin{array}{c}\text { Environmental } \\
\text { average }\end{array}$} & \multirow{2}{*}{\multicolumn{2}{|c|}{20.70}} & \multirow{2}{*}{\multicolumn{2}{|c|}{19.92}} & \multirow{2}{*}{\multicolumn{2}{|c|}{19.07}} & \multirow{2}{*}{\multicolumn{2}{|c|}{19.73}} & \multirow{2}{*}{\multicolumn{2}{|c|}{18.21}} & \multirow{2}{*}{\multicolumn{2}{|c|}{20.22}} & 19.64 & & 1.00 \\
\hline & & & & & & & & & & & & & $C$ & ence I & \\
\hline \multirow[t]{2}{*}{$\begin{array}{c}\text { Effect of } \\
\text { environment }\end{array}$} & 1.0 & & 0.2 & & -0 . & & 0. & & -1.4 & & 0.5 & & & & \\
\hline & & & & & & & & & & & & & \pm 0.75 & & $\pm \mathbf{0 . 4}$ \\
\hline
\end{tabular}

**Significant at $1 \%$ level of probability

Dry matter contents of the 15 promising potato breeding lines and commercial cultivars varied from each other. When all the environments were analyzed separately, 
it was identified that some of the advanced clones could have a dry matter ratio of over $20 \%$. These clones have the capacity to be utilized as clones with supreme dry matter content. These are PAI-8-7-49 (\% 21.96), PAI-8-9-63(\% 20.53), PAI-8-8-57 (\% 21.51), PAI-8-6-35 (\%20.42), PAI-8-15-138 (\% 20.27), PAI -8-3-15 (\% 20.20), GOU4/4 (\% 20.13), PAI-8-11-79 (\% 20.06). Results of dry matter content indicated that differences among different cultivars and promising clones were significant statistically $(\mathrm{P}<0.01)$ in all locations and years. It has been reported that late maturing cultivars accumulate higher dry matter content in cool climatic conditions and high-altitude locations. In addition, differences in quality of seed tubers affect the content of dry matter (Y1lmaz and Karan, 2011).

When the research findings are examined in regards of GEI interaction and stability of the dry matter contents, the regression coefficients varied from $\beta \mathrm{i}=0.06$ to 2.76. When the suitability in regards of dry matter ratio was examined, PAI-8-8-57 had maximum dry matter content in the suitable condition. GOU 6/28 and GOU 7/12 indicated medium adaptation in the suitable condition, PAI8-12-86 was bad adapted to favorable environments. Lady Olympia and PAI-8-6-35 had high dry matter content in the all environments. Agria, GOU 4/4 and PAI-8-3-15 were medium adapted in the all environments. GOU 6/28, PAI-8-5-34, PAI-8-1-6 and Agata produced lowest dry matter content in the all environments. PAI-8-7-49 and PAI-8-9-63 clones were superior in that they had high dry matter contents even in unfavorable conditions.

GOU4/4, PAI 8-6-35 and PAI-8-3-15 clones were superior to other clones in regards of dry matter ratio. The mean dry matter ratio of these clones in all locations and years was upward the overall mean and the regression coefficient was closest to $\beta \mathrm{i}=1$ (Table 5 and Fig. 3). Dry matter content of genotypes was affected by environment. When stability of a genotype for dry matter is high, efficient selection for specific dry matter percentages is possible (Wang et al., 2017).

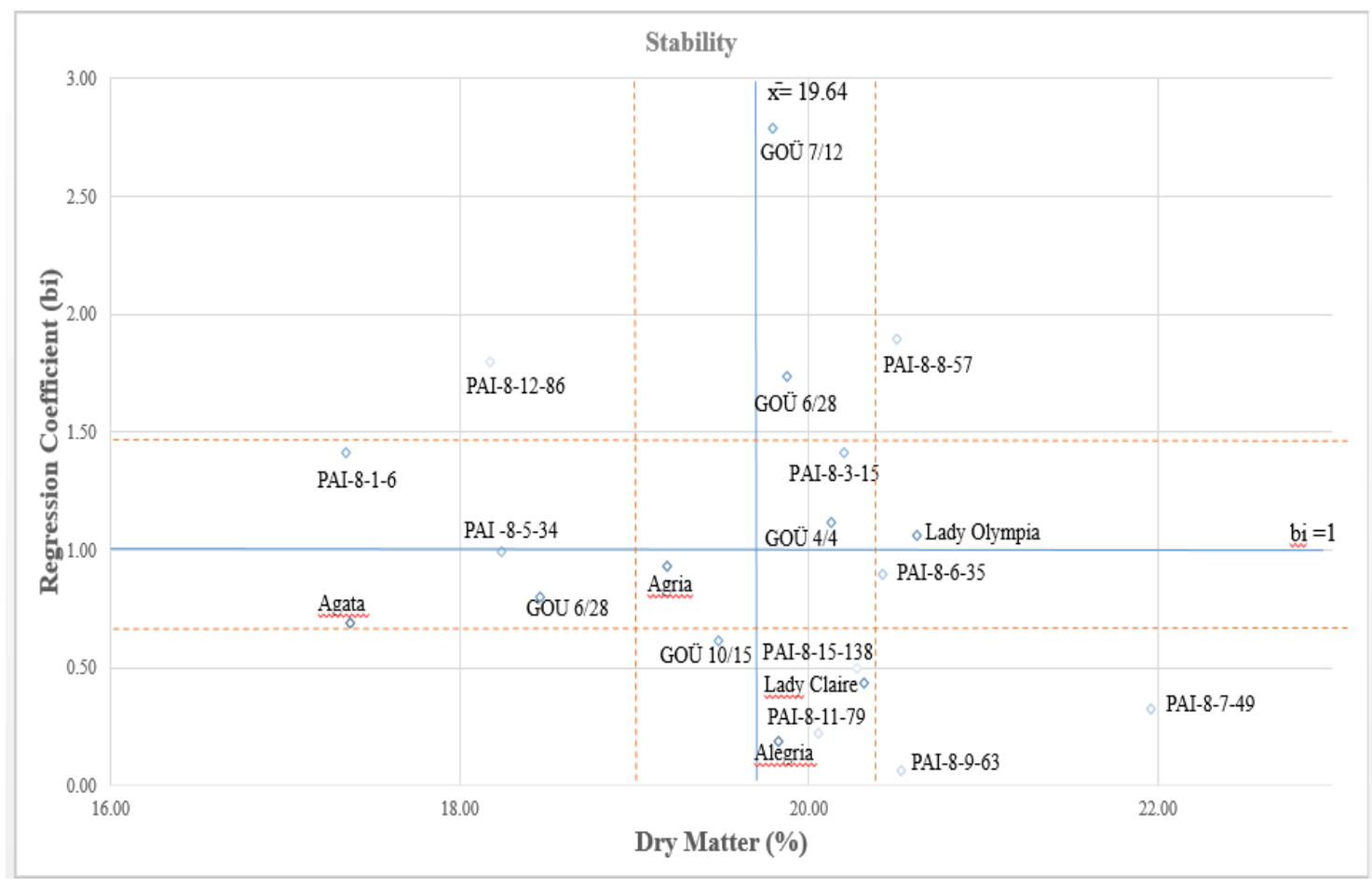

Figure 3. Adaptation classes of clone and varieties of dry matter ratio (\%) 


\section{Conclusion}

Stability of some potato cultivars was investigated by Jankowska et al. (2015). However, contrary to Jankowska et al. (2015), the genotypes in the present study were evaluated in six locations, not just in one. Generally, stability evaluation is based on the data from multi-environment experiments. To acquire reliable stability assessments, an adequate number of environments is required (Lenartowicz et al., 2020).

GEI for yield and quality is a common reality that has been showed in multiple environment experiments with a large number of species of crop plants including potato (Mallory and Porter, 2007; Mulema et al., 2008).

Field trials in this experimental were carried out in various locations in terms of different climate, weather and soil types. Based on the GEI analysis, genotypes from different programs was found to be stable for dry matter and tuber yield.

The research confirmed the presence of remarkable variation among the genotypes as dry matter ratio and for tuber yield. The genotypes were observed to have different reactions to dry matter ratio and tuber yield in the various environments. The observed significant GEI for dry matter ratio and total tuber yield indicated that potato breeders should take into account the GEI while advancing stable genotypes defined by maximum total tuber yield and dry mater content. The observed significant genotype $x$ environment interactions for dry matter ratio and total tuber yield are of major importance to plant breeders.

In all years and locations, the tuber yield average of standard varieties was 35.13 t/ha. PAI-8-8-57 (42.65 t/ha), GOU 6/28 (42.38 t/ha), PAI-8-5-34 (37.29 t/ha) and PAI-8-6-35 (35.70 t/ha) clones yielded more than the average of commercially registered varieties.

As the average of all years and locations, average dry matter of standard varieties was $19.47 \%$. The clones which were found to be superior for total tuber yield (PAI-8-857, GOU 6/28, PAI-8-5-34 and PAI-8-6-35) generally had higher dry matter contents. In addition to these clones, GOU 4/4, GOU7/12, GOU10/15, PAI-8-3-15, PAI-8-7-49, PAI-8-9-63 and PAI-8-11-79 clones had higher dry matter contents than the standard varieties.

The locations investigated were highly different from each other. While the highest total tuber yield was obtained from Artova location, the lowest total tuber yield was obtained from Erbaa location.

As a result of this research, GOU 6/28 clone have been applied to The Republic of Turkey Ministry of Agriculture and Forestry Variety Registration and Seed Certification Center for National variety of registration by Tokat Gaziosmanpasa University Faculty of Agriculture.

Acknowledgements. The authors gratefully thank The Scientific and Technological Research Council of Turkey for financial support of the Project.

\section{REFERENCES}

[1] Arshad, Y. (1990): Research on some stability parameters used to determine genotypes' adaptability. (Genotiplerin uyum yeteneklerini belirlemede kullanılan bazı stabilite parametreleri üzerine araştırmalar). - Master Thesis. Ege University, İzmir (in Turkish). 
[2] Becker, H. C., Leon, J. (1988): Stability analysis in plant breeding. - Plant Breeding 101: $1-23$.

[3] Duzgunes, O., Kesici, T., Kavuncu, O., Gürbüz, F. (1987): Research and Trial Methods. Statistical Methods-II. (Araştırma ve deneme metotları istatistik metotları-II). Publication Number: 1021, Textbook. Ankara University, Faculty of Agriculture, Ankara (in Turkish).

[4] Er, C., Uranbey, S. (1998): Starch and Sugar Plants (Nişasta ve seker bitkileri). Publication number: 1504, Textbook: 458. Ankara University, Faculty of Agriculture, Ankara (in Turkish).

[5] FAO (2018): Food and Agriculture Organization of the United Nations. http://www.fao.org/faostat/en/\#data/QC (accessed 13.07.2020).

[6] FAO (2020): Food and Agriculture Organization of the United Nations. Land \& Water. http://www.fao.org/land-water/databases-and-software/crop-information/potato/en/.

[7] Finlay, K. W., Wilkinson, G. N. (1963): The analysis of adaption in a plant breeding program. - Aust. Jour. Agric. Res. 14: 742-754.

[8] Hajianfar, R., Hassanpanah, D., Nosrati, A. E. (2017): Evaluation of advanced potato clones derived from breeding program in spring cultivated areas of Iran. - Horticultural Communication Biosci. Biotech. Res. Comm. 10(1): 127-133.

[9] Hassanabadi, H., Hassanpanah, D. (2012): Evaluation of quantitative and qualitative characters of promising potato clones in Ardabil (article in Persian with an abstract in English). - Iranian Journal of Agricultural Science. 22: 219-233.

[10] Hassanabadi, H., Hassanpanah, D. (2014): Evaluating quantitative and qualitative traits of promising potato clones and commercial cultivars using the GGE BI- plot and AMMI models. - Iranian Journal of Agricultural Science. 30: 149-164.

[11] Haverkort, A. J. (1990): Ecology of potato cropping systems in relation to latitude and altitude. Agricultural Systems 32(3): 251-72.

[12] Hongyu, K., Garcia-Pena, M., Borges, de Araújo L., do Santos, Dias, C. T. (2014): Statistical analysis of yield trials by AMMI analysis of genotype $\times$ environment interaction. - Biometrical Letters 51(2): 89-102.

[13] Hoopes, R. W., Plaisted, R. L. (1987): Potato. Chap. 11. - In: W. R. Fehr (ed.) Principles of Cultivar Development. Vol. 2. Macmillan, New York.

[14] Ikiz, F. (1972): Genotype-environment interactions (Genotip-cevre interaksiyonları). Plant breeding seminar. - Turkey Association of Agricultural Researchers Publications, Bornova-Izmir, pp. 207-226 (in Turkish).

[15] Ikiz, F. (1976): Genotype x environment interaction statistics in wheat breeding (Bugday islahinda genotip $\mathrm{x}$ cevre interaksiyonu istatistik analizleri). - PhD Thesis. Ege University, Faculty of Agriculture, Agronomy Genetics Course, İzmir (in Turkish).

[16] Jankowska, J., Pietraszko, M., Lutomirska, B. (2015): The analysis of yielding stability of some potato (Solanum tuberosum L.) cultivars on light soils. - Fragm Agron 32: 32-43 (in Polish).

[17] Lenartowicz, T., Piepho, H. P., Przystalki, M. (2020): Stability analysis of tuber yield and starch yield in mid-late and late maturing starch cultivars of potato (Solanum tuberosum). - Potato Research 63(2): 179-197.

[18] Lin, C. S., Binns, M. R., Lefkovitch, L. P. (1986): Stability analysis: where do we stand? - Crop Science 26: 894-899.

[19] Mallory, E. L., Porter, G. A. (2007): Potato yield stability under contrasting soil management strategies. - Agronomy Journal 99: 501-510.

[20] Martin, F. W., Flores, N. A., Carmer, S. G. (1988): Identification of the key environment for determination of yield stability in sweet potato. - Trap. Agric. (Trinidad) 65: 313-316.

[21] Meijers, C. P., van Veldhuisen, G. (1972): De spreiding van de soortelijke gewichten van aardappelen. - Bedrijfsontwikkeling 3: 813-818 (in Dutch). 
[22] Mulema, J. M. K., Adipala, E., Olanya, O. M., Wagoire, W. (2008): Yield stability analysis of late blight resistant potato selections. - Journal of Experimental Agriculture 44(2): 145-155.

[23] Niringiye, C. S., Ssemakula, G. N., Namakula, J., Kigozi, C. B., Alajo, A., Mpembe, I., Mwanga, R. O. M. (2014): Evaluation of promising sweet potato clones in selected agro ecological zones of Uganda. - Time Journals of Agriculture and Veterinary Sciences 2(3): 81-88.

[24] Roostaei, M., Mohammadi, R., Amri, A. (2014): Rank correlation among different statistical models in ranking of winter wheat genotypes. - The Crop Journal 2: 154-163. http://dx.doi.org/10.1016/j. cj.2014.02.002.

[25] Ruswandi, D., Anggia, E., Hastini, T., Suhada, A., Istifadah, N., Ismail, A., Suryadi, E., Ruswandi, S., Rostini, D. N. (2008): Selection of DR Unpad field corn hybrids based on their yield stabilities and adaptabilities in eight location in Indonesia. - Zuriat 19(1): 7185.

[26] Stol, W., de Koning, G. H. J., Kooman, P. L., Haverkort, A. J., van Keulen, H., Penning de Vries FWT (1991): Agro-Ecological Characterization for Potato Production. - Centre for Agrobiological Research (CABO-DLO) Wageningen.

[27] Tugay, M. E., Citir, A., Yilmaz, G., Çagatay, K., Kara, K. (1995): Research on seed potato production. (Tohumluk Patates Uretimi Uzerine Arastirmalar). - The Scientific and Technological Research Council of Turkey (TUBITAK). Final Report of the Project no 950. Gaziosmanpasa University, Faculty of Agriculture (in Turkish).

[28] Turkish State Meteorological Service (TSMS) (2018): Meteorological District Office of Record of Climate Data, Tokat (in Turkish).

[29] Vander Zaag, D. E. (1984): Reliability and significance of a simple method of estimating the potential yield of the potato crop. - Potato Research 27: 51-73.

[30] Wang, Y., Snodgrass, L. B., Bethke, P. C., Bussan, A. J., Holm, D., Novy, R. G., Pavek, M. J., Porter, G. A., Rosen, C. J., Sathuvalli, V., Thompson, A. L., Thornton, M. T., Endelman, J. B. (2017): Reliability of measurement and genotypexenvironment interaction for potato specific gravity. - Crop Science 57: 1-7.

[31] Yildirim, M. B., Ozturk, A., Ikiz, F., Puskulcu, H. (1979): Statistical-Genetic Methods in Plant Breeding. (Bitki Islahinda Istatistik-Genetik Yontemler). - Publication No: 20. Aegean Regional Agricultural Research Institute, Menemen, İzmir (in Turkish).

[32] Yilmaz, G., Karan, Y. B. (2011): The performance of seed potato (Solanum tubersoum) produced in different production areas in Turkey- Tokat- Artova conditions. International I. Ali Numan Kirac Agriculture Congress, Eskisehir, 27-30 April (in Turkish). 